of the falling water failing to produce any effect on him. Urine: Sp. gr. 1035; abundant sediment of urates; no albumen, but precipitates urea abundantly. Pulse 108; temperature $101^{\circ}$.- 1 P.M. : Requested his minister to be sent for, and on first seeing him he was seized with a severe spasm, which soon passed off, when he spoke calmly of his approaching death. At 3 P.M. he absolutely refuced either beef-tea or milk. Pulse 96 ; temperature $100^{\circ} .-9$ P.M. : I saw him again, and on offering him some milk he consented to try to swallow it, but on doing so the whole of the milk was violently ejected, a severe spasm following, which, on subsiding, was followed, not by the usual sigh, but by a peculiar, prolonged sound, which resembled nothing so much as the baying of a dog as heard at a distance on a calm summer night in the country. He was ordered to be placed under the influence of chloroform, and eight ounces of beef-tea and some port wine to be thrown into the stomach by the tube, which was done at 10 P.M. On recovering from the immediate effects of the chloroform he vomited everything and became wildly delirous, and the spasms recurred frequently. Wishes to leave the room, and fancies he is fighting with those around him.

31st.-1.30 A.M. : Very restless. Complains of great thirst. Continually endeavouring to cough up a fly from his throat, which, he says, is choking him. He expectorates some blood-tinged mucus. Pulse nearly 140, but difficulty encountered in reckoning on account of his extreme restlessness. Urine loaded, sp. gr. 1035, highly alkaline; no albumen; sediment, which seems to consist of urates and phosphates (chiefly the latter), and, under the microscope, triple phosphates and little globular masses (urate of soda or carbonate of lime).--2 P.M. : A decided change has taken place; patient has taken some beef-tea with little or no spasm.6 P.Mr. : Requested the house-surgeon to write to his wife, and he himself wrote his name in the journal with a steady hand. Speaks cheerfully. Pulse 140 ; temperature $101 \cdot 6^{\circ}$. 9 P.Mr.: On visiting, the house-surgeon and nurse met me in the lobby, both exclaiming that McG- was better. On entering the side room he at once sat up in bed and held out his hand to me, saying, "I'm quite better, Sir." He reached for the drinking cup and drank freely of beef-tea without any spasm whatever. He mentioned that Dr. Macgill had been up to see him, and in the event of his recovering he was to have a month's leave, at the thought of which he seemed highly pleased. He now talked incessantly but rationally, and all appearance of dread had disappeared. Pulse 140. - Midnight : Patient again wildly delirious at times, at others rational. Asks to be tied, lest he should harm anyone near him; this, however, was not required. He says he thinks he should not have been ill had he not read of the second case at the Royal Infirmary. Pulse 150.

Nov. 1st.-Fell asleep at 4, and slept till 7, at which time he had a long epileptiform fit. At 8.30 he became gradually semi-comatose, his skin being covered with a clammy perspiration until 10 A.M., when he died.

His bowels were opened once, and he passed urine voluntarily all through the case.

The post-mortem examination took place on Nov. 2nd, at 10.30 A.Mr.; Dr. Dunlop, Dr. Coats, and myself being present. Every organ in the body was healthy. The brain and its membranes were slightly congested, which may have been the effect, rather than the cause, of the disease.

\section{REPORT ON THE PATHOLOGY OF THE DISEASE.}

$$
\text { BX DR. JOSEPH COATS, }
$$

PATHOLOGIST TO THE WESTEBN INFIRMABT.

As the lesion found in the two cases of hydrophobia is possibly of some consequence, and as a case of hydrophobia in the dog is at present under investigation, it is proposed to embody the full results in a more purely pathological paper, where the condition of parts may be more completely illustrated. In the meantime, the general results may be given, and some reference made to the bearing these have on the pathology of the disease.

The writer vade the post-mortem examination in Dr. Patterson's case, and he had the opportunity of examining the parts in Dr. Dunlop's case, through the kindness of Dr. Foulis. At the post-mortem of Dr. Patterson's case, the following conditions were noted:-There was some ecchymosis of the skin over the left costal margin. A small cicatrix existed on the dorsal aspect of the left hand over the distal extremity of the metacarpal bone of the index finger, and there were one or two small depressions slightly above this. Under the external aspect of the nail of the left thumb was some altered blood, and the nail was partially loosened. The organs of the chest and abdomen were, to all appearance, perfectly normal with the exception of slight hypostatic engorgement of the lungs. The veins of the encephalon were distended with blood, which, in the longi. tudinal sinus at least, was fluid. The surface of the arachnoid was smeared with blood-tinged fluid over the hemispheres, and there were a few ounces of similar fluid in the ventricles. Portions of the nervous system, the cicatrix and skin around it, with the corresponding nerve up as high as the elbow, were preserved and hardened in alcohol and chromic acid solution.

Microscopic appearances.-The cicatrix and skin around it were examined in Dr. Patterson's case, and certain parts of the nervous system in both. In the neighbourhood of the cicatrix, and for about an inch in every direction around it, the skin and subcutaneous fat presented evidence of irritation, these structures being infiltrated with round cells, which in some parts were so abundant as to have caused absorption of the fat, the adipose tissue being replaced by round cells. In addition there were some bloodvessels which contained disintegrated blood-clot, and these vessels presented a peculiar condition, which I have seen in other parts, but have been inclined to ascribe to post-mortem changes; but Dr. Thomas Reid assures me that he has often seen it in the inflamed conjunctiva when examined immediately after removal from living persons. It consists in a production of clear, transparent, globular bodies, which look like drops of an exuded fluid, just inside the blood. vessels along their internal wall. In respect to the nerrous system there was found in both cases, at very frequent in. tervals, an accumulation of round cells in the perivascular spaces of the medium-sized vessels. In the regions affected this lesion was by no means continuous, and it also presented great varieties in degree. In some sections there were at one side of the vessel a few corpuscles lying loosely outside the wall. From this there were all degrees of the lesion, till in some specimens these bodies formed a thick mantle around the vessel, lying in masses several rows deep. This lesion was not confined to the medulla oblongata,

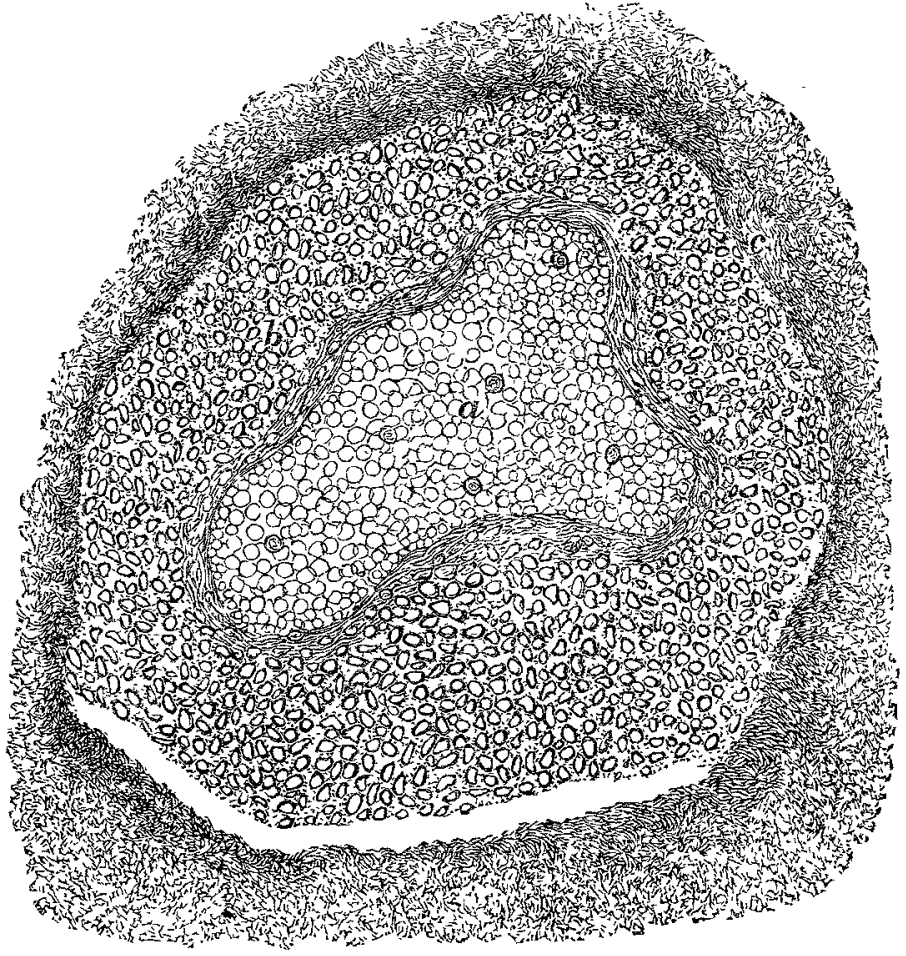

Lesion in the nervous system referred to in the text. $-a$, Blood. vessel containing red and a few white corpuscles. $b$, Round ressei containg rod and a few white corpuscles. b, hound chas act specimen figared here was taken from the cervical region of the cord. Here, as well as in the medulla oblongata, lesion of similar or greater intensity were frequent. The section was glycerine.

but existed in the cord as low down as the middle of the dorsal lesion, and in the pons and crura cerebri. In the convolutions it was only present in a very minor degree. 
Besides the lesion there was a similar accumulation of round cells in the spaces around the ganglion cells. In some instances these were present in very large numbers, so as nearly to bury the cell, but in very many parts this lesion was entirely absent. The localisation of it has not yet been wrought out. In addition there were in all the parts of the nervous system examined vast numbers of amyloid bodies, but as these are so common in various diseases, I could not attach great importance to them. In only one of the numerous sections made was there any hæmorrhage dis. covered. There was no lesion of the nerves of the hand or arm, not even of those in the immediate neighbourhood of the cicatrix.

Remarks on the pathology of the disease.-The conditions related seem to indicate that there was a more or less persistent irritation in the neighbourhood of the scar, presumably caused by the virus introduced by the teeth of the dog. This virus had been absorbed, and the condition of the vessels near the scar, described above, may or may not be connected with this process of absorption. The so-called period of latency is probably the time during which the virus remains local, and the great differences in this period are quite consistent with what we find in other diseases. In local tuberculosis, for instance, the disease may remain local for years, or it may suddenly become generalised, and an acute tuberculosis develop, this being due to the infective material of tubercle finding its way into the general circulation. Just as tuberculosis may remain local, so, probably, may hydrophobia. But when the virus has got into the bloodvessels it will be carried to the various parts of the body. The lesions found in the nervous system in both these cases are evidence of irritation of the bloodvessels, and it is to be presumed that wherever the bloodvessels are delicate they will be similarly irritated, and give rise to similar lesions. This general irritation may explain the fever which seems to be always present in hydrophobia. It need not surprise us, supposing a lesion of this kind to exist in various organs, that the symptoms are yet mainly referable to the central nervous system. A lesion which will produce almost no effect in the liver might be a very serious one in the central nervous system. So is it, for instance, with tubercles, which may exist in myriads in the liver without any symptoms to speak of, but in the pia mater they produce tubercular meningitis. $T$ have been therefore prepared to find lesions analogous to those in the nervous system in other organs, and I find that in the literature of the subject there are references to such lesions. I find, moreover, that in a dog which was killed because of hydrophobia, and which I have not yet fully investigated, there are lesions of a kind similar to those described in other parts as well as in the nervous system. This disease, hydrophobia, may, I think, be contrasted in its pathology with tetanus. In tetanus we have a definite irritation of the nerves connected with the injured part, and in several thoroughly investigated cases there has been an actual inflammation described. In hydrophobia the nerres do not seem to be specially involved; for, though there are abnormal sensations in the part, these appear to be rather of the nature of an indefinite stinging or peculiar feeling. In the above case the nerves of the part seemed to present nothing abnormal. Hydrophobia seems, therefore, to be rather an infective disease. The virus is introduced into the skin, and may possibly go no further, producing only irritation there. But getting into the general vascular system, it produces lesions which seem to be immediately related to the bloodvessels. These lesions in the central nerrous system seem to be the causes of the peculiar symptoms in this disease.

Bequests \&C. to Medical Charities.-Miss Baxter has given $£ 0000$ to the endowment fund of the Convalescent Hospital at Dundee, founded by her brother, the late Sir David Baxter. The Rotherham Hospital and Dispensary has received $£ 1000$ from Mr. T. Marrian, and become entitled to $\$ 1000$ under the will of $\mathrm{Mr}$. Liversedge. The Sheffeld General Infirmary has received $\$ 630$ under the will of Mr. Rubert Waters. The Queen's Hospital, Birmingham, has received $£ 220$ under the will of Mr. William Dudley, and \&200 under that of Mr. Thomas C. Osler. The Eastern Dispensary, Bath, has received $\$ 500$ under the will of Mrs. Harrington, and \&100 under that of Mr. Ripley.

\section{dy aftirror}

\section{HOSPITAL PRACTICE,} BRITISH AND FOREIGN.

Nulla antem est alia pro certo noseendi via, nisi quamplurimas et morbornm et dissectionum historias, tum aliorum, tum proprias collectas habere, et inter se comparare,-MosGLGMI De Sed. et Caus. MTorb., lib. iv. Procmium.

\section{CHARING-CROSS HOSPITAL.}

FEMORAL HERNIA, WITH A DIVERTICULUM THROUGH THE SUPERFICIAL FASCIA ; STRANGULATION ; OPERATION ; RECOVERY. (COOPER'S HERNIA.)

(Under the care of Mr. Bellamy.)

Cases in which the strangulation of intestine or omentum is due to the influence of some band or process of superficial fascia beyond, and external to, any one of the usual tissues forming the wall of the canal, are comparatively rare, and the diagnosis of the actual seat of stricture is thus rendered more difficult.

Mrs. W- aged fifty-five, was admitted Jan. 4th, 1877 , with all the symptoms of strangulated hernia, the reduction of which oy the taxis some hours before she came to the hospital had failed. On examination, two large tumours were found in the region of the groin-one external, about as large as an orange, very tense and inflamed, with a slightly ulcerated surface; and a second tumour internal to it, situated above the symphysis pubis, and separated from the former by a deep sulcus (evidently the site of the edge of the vulval aponeurosis), which was thickened and rendered more tough and unyielding by the presence of a cicatrix which was adherent to the subjacent tissues. This cicatrix was the remains of a previous operation for strangulated hernia. Alternate pressure upon the tumours clearly showed them to be connected.

Mr. Bellamy diagnosed a femoral hernia deflected from its usual course, directly over Poupart's ligament, and which had taken a direction upwards and inwards, probably constricted by a fascial band, and evidently strangulated. However, after the amount of taxis which had been applied, he deemed it more judicious to operate at once. Chloroform being administered, he made an incision about three inches long with a bistoury directly through the tough tissues forming the sulcus, down upon the sac, which had the effect of instantly liberating the constriction and of converting the two masses into a single tumour. The inner portion of this consisted of a large knuckle of gut on the verge of strangulation, whilst the external-the one emerging from the saphenous opening-consisted of a coil of gut and a large quantity of omentum, which was highly injected. After gently attempting reduction without success, he divided the sac, from the cavity of which a large quantity of serum escaped; the bowel was then reduced partially, but it was found necessary to nick the edges both of Hey's and Gimbernat's ligaments before both gut and omentum could be entirely replaced within the abdominal cavity. There was no hæmorrhage whatever, the external wound was united with a wire stitch, a pad and spica bandage applied, and a full dose of opium administered. The next day she was very comfortable, although there had been a slight attempt at retching, and her evening temperature rose to $101^{\circ}$. On the 7 th the temperature was normal, and she passed a natural motion.

She improved from day to day, and is now (Jan. 20th) convalescent.

\section{GENERAL HOSPITAL, NOTTINGHAM.}

ANEURISM OF THE FEMORAL ARTERY TREATED BY ESMARCH's BANDAGE; RECOVERY.

(Under the care of Mr. Thomas WRIGHT.)

For the notes of the following case we are indebted to Dr. Lewis W. Marshall, resident surgeon.

William $\mathrm{S} \longrightarrow$, aged thirty-nine, a fitter, was admitted on Nov. 1st, 1876, with a tumour on the inside of the left thigh presenting all the signs of aneurism in Hunter's canal. 